\title{
Life and Death Matters: Human Rights and the Environment at the End of the Millennium. Barbara Rose Johnston, editor. 1997. Walnut Creek, London, New Delhi: Altamira Press. 350 pp.
}

\author{
Reviewed by Diana Pritchard, Indiana University.
}

Contrary to modernity's quintessential promise of progress, it is clear from the atrocities wrought on human and ecological communities around the global that life on this planet for the majority of people does not get better. The closure of the century provides an opportune moment for reflection on the human condition. This book sets itself the task of contributing to such a discussion by examining the distinct actions of people attempting to survive crisis-ridden circumstances. It comprises a collection of 14 case studies from around the world, focusing on the experiences of grassroots organizational efforts. These illustrate peoples' efforts to ameliorate the devastation and conflicts emerging from, amongst other things, biodiversity preservation (Derman and Hitchcock), mineral extraction (Sponsel and Gedicks), agricultural resources (Wheeler and Esainko; Phillips); violence towards indigenous peoples (Pi-Sunyer and Brooke Thomas; Stea, Elguea and Perez Bustillo), forced migration (Aragon), tourism (Swope, Byrne Swain, Fuquan Yang and Ives), post war reconstruction (McSpadden and Wisner), radiation experimentation (Barker), and nuclear contamination (Garb).

As with all such volumes of contributions originally presented in conference sessions, a strong editorial hand is required. It is especially important to generate accompanying text that can render coherent otherwise motley collections that contain a diversity of themes and regions. Unfortunately, despite these being sound papers, editor Johnston fails to provide a solid analytical framework to advance our understanding of their significance in this volume. This is particularly notable in the introduction. Although the book claims to have human environmental crises as its central analytical focus, the editor omits even a basic conceptual framework with which to associate human rights abuse and environmental destruction. She opts instead to merely tag the UN Human Rights Declaration on as an appendix, without explanatory narrative. As a consequence, the ethical and legal significance of perceiving human rights as an extended principle that "should include an ecologically sound environment, sustainable development and peace," as promoted by the corresponding commission, is lost. With it, is lost the opportunity to highlight the obviously anthropocentric assumptions that are implicit in the collection, namely that the environment is valuable because of its use to humankind. However, this is just one of many central notions glossed over in the introductory essay.

A more suitable introduction also would have provided the appropriate conceptual tools to enable readers to explore the case material and consider how the status and complexities of human and environmental rights are linked to wider phenomena. Instead there is an odd array of subsections touching a range of notions such as "Culture and Structures of Power," and "Physical Mechanisms." At one and two paragraphs long, respectively, they are too brief and inadequately developed to generate anything other than confusion about their relevance. 
Though the book also states that it will explore the tension between "global processes" and human responses, there is no further elaboration of precisely what these constitute. To the contrary, in an apparent rejection of positivist theories, there is no mention of crucial structures and networks, including globalized capitalist relations, the international division of labor, resources and world communication systems. This is counter productive because it inhibits readers from making links about the underlying factors that not only generate human environmental crises but also shape the strategies developed by people to confront them. Moreover, without reference to these globalized relations, readers are unable to interpret the historical significance of our present day world. Consequently, we are offered no help in our reflections on whether it is business as usual for humanity; if there is something more pernicious at work in the world today and if there is anything new about the way people organize in the late 1990s. Nor can we appreciate how relations might have changed between countries in north and south, between citizens and the states, between citizens and international organizations.

At first glance it seems fair to conclude that the contributors have agreed to abandon the intellectual foundations of modernity. Perhaps the evidence would warrant it. After all, its scientific knowledge has not necessarily been advanced for the service of either humanity or the environment on which it depends, and its theories have not proved successful in explaining our world. Yet the book's emphasis on the importance of stories of peoples' experiences is incomplete. Nowhere does the book seek to advance the idea that a focus on subjective, not structural, phenomena, matters. To the contrary, instead of an elaboration of this approach, we encounter one of many contradictions in this book: that ultimately it does have a very empirical concern, namely, to identify what makes for effective action. More problematic still, and in keeping with postmodern tradition, we are subject to three painful pages of a dire form of reflexivity. If ever there was a leastappropriate place for an introduction which lingers on the editor's own personal trip into the world of social and environmental hardship and crisis, this is it. It contrasts starkly with the "reality" of the life-and-death struggles of the subjects of the book.

Such shortcomings ensure that the conclusion, titled clumsily "Crisis, Chaos, Conflict, and Change," is doomed. Though it goes some way to unite papers by highlighting a range of responses (from passive resistance, organized efforts to modify systems, confrontational efforts to attempts to reconstruct power), it cannot salvage the book. It is not only too short to be able to do anything satisfactorily, it is also studded with the typically undisciplined statements that characterize the editorial text. For example, in citing a "promising" scenario, Johnston points to people's participation in the planning of projects. This is then followed by the statement: "This is community-based environmental restoration, and this is nation building." The claim verges on the academically irresponsible as it is laden with theoretical assumptions that would have to be outlined in order to make any sense.

As interesting as each case study is, the book stands as an overly dramatic and underanalyzed series of snippets. In the apparent attempt to stir up western privileged sympathies, Johnston appears to have abandoned all serious analytical rigor. Though she might have aimed to tweak the conscience of corporate interests or shame policy makers, their engagement may be lost as a consequence. 